\title{
Multipurpose Learning Environments for Flexible Didactics
}

\author{
Anna Celeste Rubino
}

\begin{abstract}
This paper investigates some of the issues and good practices in which 21 st-century educational requirements are met by innovative design solutions for learning spaces, and their implications for education.
\end{abstract}

Keywords Learning environment $\cdot$ Pedagogy $\cdot$ Space design $\cdot$ Multifunction Flexibility

\section{Introduction}

In recent decades, there has been much debate in the fields of architecture and pedagogy on the conception and design of new learning spaces, with an attempt to opportunely encompass all the elements that should contribute to an effective learning process.

The main considerations for such design include pedagogy, the technological tools used in teaching, the need for flexible and adaptable educational spaces in the different urban and social contexts of contemporary society.

What is the role of contemporary architecture in rethinking learning spaces? Can it influence learning processes or should it support pedagogical needs?

According to Gislason, most studies show that the changes introduced in the field of teaching and learning in the last two centuries have influenced the architecture of schools and the design of classrooms. He outlines two main transformations in the relationship between school design and school culture in western countries: the transition from single-grade classrooms to multi-grade school-rooms, and the spread of innovative educational practices, as an alternative to frontal lessons, such as cooperative education and informal learning activities [1].

\footnotetext{
A. C. Rubino ( $\varangle)$

DICEA-Dipartimento di Ingegneria Edile Architettura, Università Politecnica delle Marche, Ancona, Italy

e-mail: a.c.rubino@pm.univpm.it
} 
These variations have required a rethinking of learning spaces, involving space design experts and paving the way for interactions between the pedagogy and architecture sectors.

\section{Pedagogy and Space Design in 21st-Century Learning}

\subsection{Critical Issues and New Requirements}

It has recently become widespread practice in different European contexts for school designers to ask teachers and students what their needs are for new spaces, in an attempt to implement participatory planning.

Nevertheless, the link between architecture and the educational community is still characterized by distance and criticalities, and the word architecture is not widely used in the context of contemporary educational theories. The preference in educational environments is to refer to the building in its entirety, by calling it a "structure", or to specific elements of the learning environment, such as the tools used daily for teaching, referred to as resources [2].

One critical element is the difficulty teachers have designing and implementing non-traditional didactics, and adequately using the tools and spaces designed for active and collaborative teaching [3].

Another open issue is the inadequate level of communication and mutual understanding between the world of architecture and the world of education.

Teachers' requests regarding the arrangement of spaces for functional learning environments that are psychologically comfortable for students are not always properly interpreted and converted into architectural spaces.

The influence of social media and digital technologies is also a significant factor in the radical changes to the 21 st-century learning environment.

Since the 1980s, Meyrowitz has illustrated that television and electronic media have altered social and communicative behavior, by dematerializing the boundaries between childhood and adulthood, and between private and public space [4].

An aptitude for using social media and the portability for students of smartphones have contributed to the breaking down of barriers between adults and children, determining the idea of deterritorialization and disembodiment of space in the digital landscape [5].

The traditional class space is seen as increasingly porous and precarious, owing to the ease and speed with which information can be shared between the worlds inside and outside school [6].

Demand in the twentieth century for child-centered pedagogy and the diversification and personalization of learning, as well as the use of visual technologies are altering the experience and aspirations of learners [7]. 


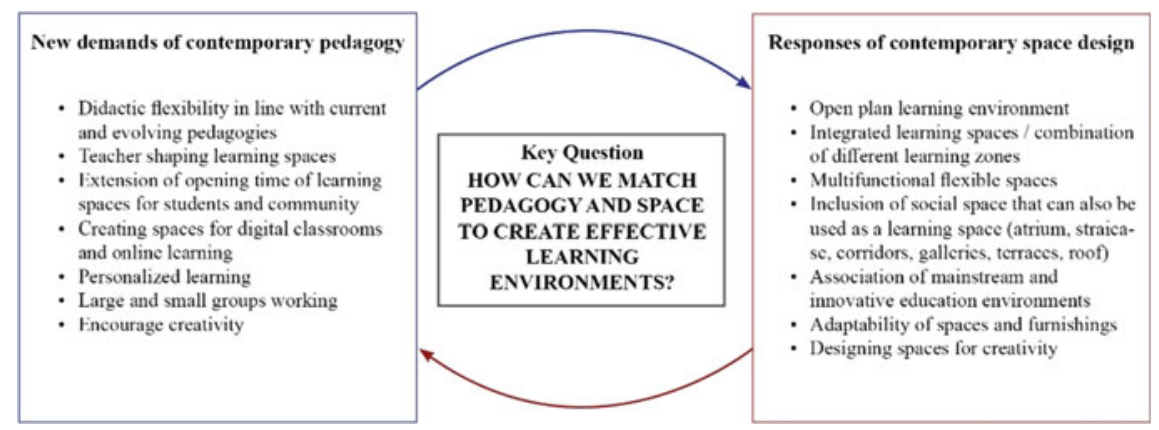

Fig. 1 The diagram summarizes recent demands made with respect to the architecture of learning environments within schools (author's diagram)

\subsection{Combining Pedagogies and Spaces}

The research focused on investigating how the configuration of contemporary educational spaces meets changing educational needs, from both a pedagogical and an architectural point of view (Fig. 1).

The classroom is the traditional teaching space and has been the subject of various experiments over time. However, there has been a recent trend in contemporary European schools to expand the educational space to the entire school building, including closed and open spaces, pre-existing buildings and newly built spaces.

The connective spaces also tend to be considered suitable for teaching, so much so that there is a growing trend for the hybrid use of learning spaces. These might be, for example, wide staircases used in multiple ways, as a space for taught lessons or collaborative lessons, as a lecture theatre for conferences and meetings, or simply as a socialization space for students.

In the current scenario of school architecture, there is a need to expand the physical learning space to include a variety of informal and social areas [3].

\section{Multifunctional Learning Spaces in Contemporary Education Environments}

Recent projects in different grades of school and university spaces include design solutions of this kind and the possibility for a flexible use of space both vertically and horizontally.

At Lorentz School in Leiden, Netherlands, designed by the architectural firm atelier PRO, the auditorium space was used for multiple purposes, in addition to its traditional function. These include: a theatre, a documentation center and library, and a space for computer lessons, as it contains workstations [8] (Fig. 2). 
a

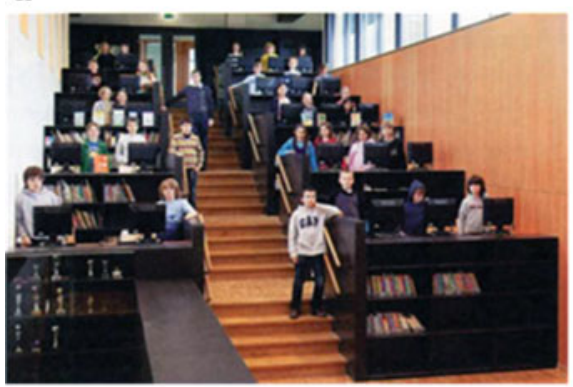

b

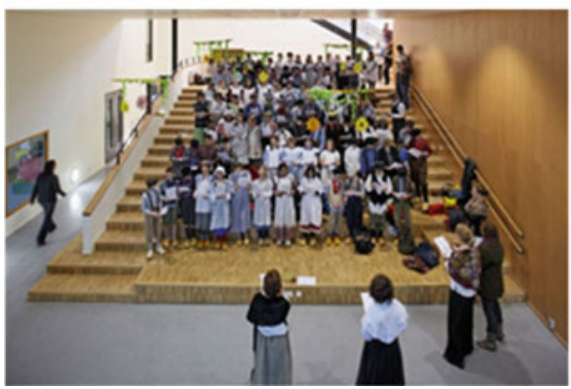

C

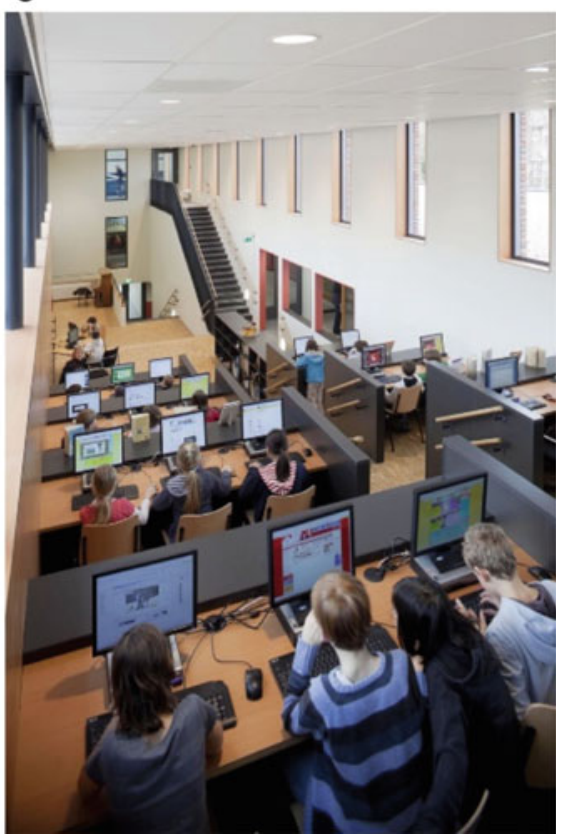

Fig. 2 a The documentation center also used for computer lessons at Lorentz School, Leiden, Netherlands (photo: Jannes Linders). b The auditorium used for performances at Lorentz School (photo: Jannes Linders). c Mediatheek on the stairs at Lorentz School (photo: Jannes Linders)

An area of experimentation of different learning spaces is the Bartlett Real Estate Institute (BREI), a new Centre for Learning Environments of University College London (UCL) located on the first floor of Here East university campus in East London, in a converted, multifunctional building erected for the 2012 London Olympics.

The variety of learning spaces is based on a holistic vision, to provide a 21 stcentury collaborative and inclusive environment for students, academics, designers and professionals involved in space investigation and design. In addition to open areas for panel debates and networking, fitted with a display screen, there are seminar rooms, a lecture theater and private study booths.

On the ground floor, wide spaces support flexible functions, such as the auditorium space, used for conferences and events, as an individual and group study space for university students, and as a laboratory space for secondary school students during the summer school.

An uncommon example of school architecture is the Bridge Academy, a public high school in the north-east London borough of Hackney.

The unusual location of the school on the banks of Regent's Canal led BDP architects to build vertically, distributing the classrooms and the open learning spaces 
a

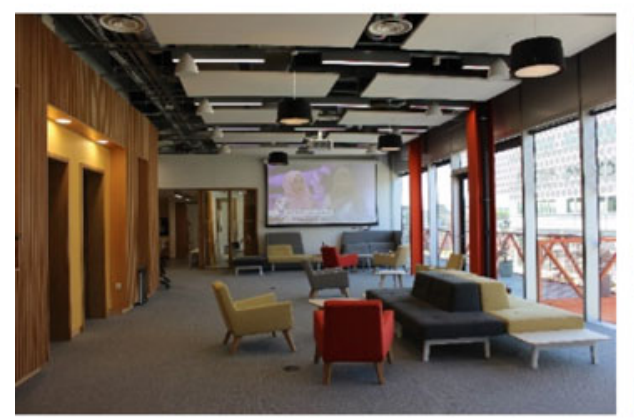

C

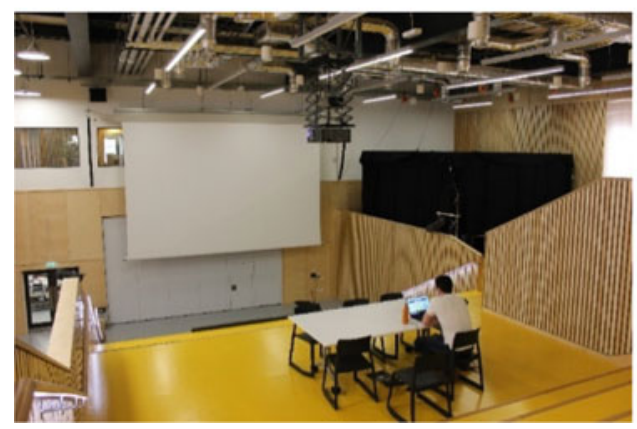

b

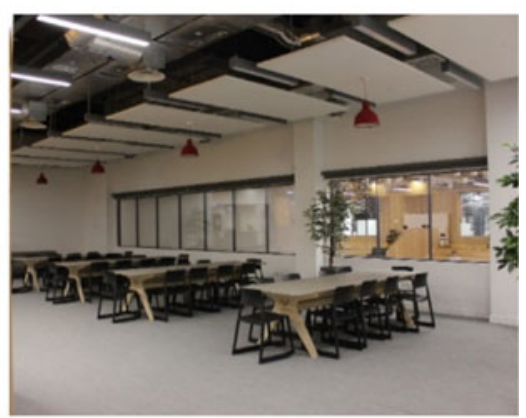

d

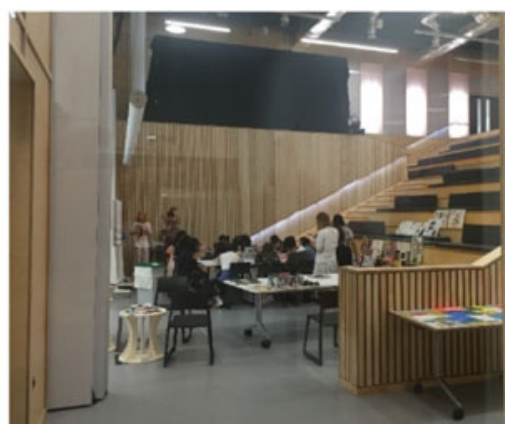

Fig. 3 a The break-out area in Bartlett Real Estate Institute (BREI) at UCL Here East, London (photo: Anna Celeste Rubino). b The lounge in BREI (photo: Anna Celeste Rubino). c The auditorium on the ground floor of UCL Here East (photo: Anna Celeste Rubino). d The auditorium used by secondary school students (photo: Anna Celeste Rubino)

over different floors, and connecting them physically via open balcony corridors (Fig. 3).

Owing to the building's geometry, most classrooms and learning zones in the galleries have irregular shapes, providing formal and informal learning environments [9] (Fig. 4).

The six floors face onto a ground floor "central square", a social heart space used for assemblies and recreation, above which the library is suspended. Both constitute centralized areas of focus within the school where learning and social activities can take place. The architect Papa of BDP, part of the Bridge Academy design team, said about the fundamental aspects of the project: "We get inspiration and some specific concepts of architecture on the part of... designing the school... from one particular architect who influenced us both in this school and others that we've designed, which is Herman Hertzberger. The Montessori School in Amsterdam is very interesting particularly for two key concepts: first it is very focused around a space or a unifying idea that the whole school is one thing and you should really be able to stand in one part of the school see the rest of it in one glance. Second is 
a

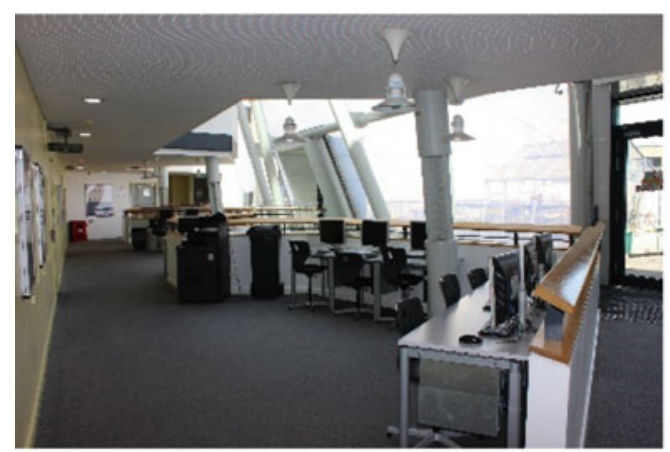

b

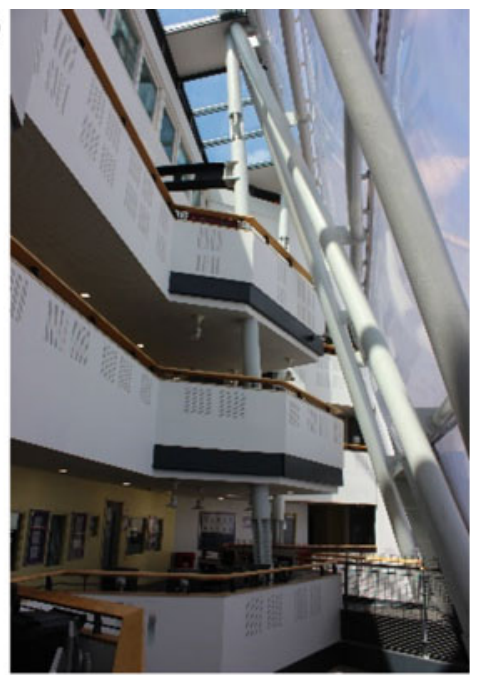

C

d
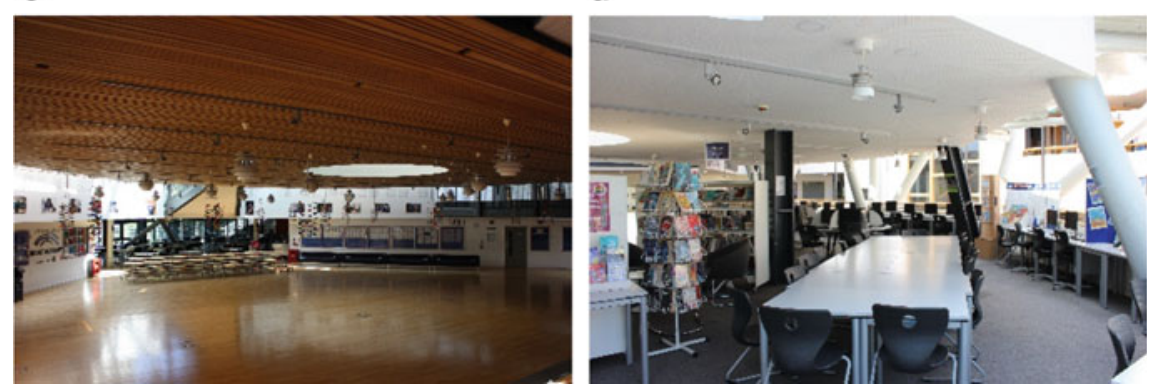

Fig. 4 a One of the many open learning zones with workstation in the galleries of Bridge Academy, London (photo: Anna Celeste Rubino). b View of galleries on different floors at Bridge Academy (photo: Anna Celeste Rubino). c Ground floor hall, as a "central square" making an impressive spatial impact, Bridge Academy (photo: Anna Celeste Rubino). d The library floor overhanging the assembly hall (photo: Anna Celeste Rubino)

the staircase's location in different points of each level; it means you going... this staircase is... you're always heading towards another set of teaching and learning spaces and you never have that feeling of going round" [Interview transcript, Papa, Keith (interviewee), Rubino, Anna C. (interviewer), 2019]. 


\section{Conclusions}

The projects involving school and university spaces presented here contribute to defining a concept of contemporary learning spaces that responds to the needs of today's increasingly multicultural, dynamic and connected society. In light of the foregoing, the learning space is to be considered one that is socially constructed through student and community practices and multiple social relationships with variable layouts; the architectural dimension takes on multiple dimensions, with fluid internal and external boundaries, and incorporating different areas of proxemics. Designers and educational institutions should promote the creation of learning spaces of different sizes and with different equipment and furnishings. Such spaces might communicate with each other, favoring spatial fluidity, or be separated by walls or mobile panels. Furnishings should also be flexible and varied, to encourage autonomous use of the space by students, as well as an active willingness to adapt the conditions of comfort in the classroom and laboratories. There is a common denominator to many contemporary school and university projects: the presence of large halls and spaces for multiple uses both inside and outside buildings, for use by students, staff and local communities, can respond effectively to the increasing demand for social learning spaces.

The learning environments analyzed show a flexible and creative approach on the part of architecture, in an attempt to meet the needs of 21 st-century education.

\section{References}

1. Gislason, N.: Building Innovation. History, Cases, and Perspectives on School Design, Backalong Books, Big Tancook Island, Canada (2011)

2. Dudek, M.: How Children Learn from Architecture and the Environment, Routledge, Taylor \& Francis Group, UK (2019)

3. Mirchandani, N., Wright, S.: Future schools. Innovative Design for Existing and New Buildings, pp. 31-88. RIBA Publishing, part of RIBA Enterprises Ltd, Newcastle upon Tyne, UK (2016)

4. Meyrowitz, J.: No Sense of Place: The Impact of Electronic Media on Social Behaviour. Oxford University Press, Oxford, UK (1985)

5. Castells, M.: The Rise of the Network Society. Blackwell, Oxford, UK (2000)

6. Dussel, I.: Digital classrooms and the new economies of attention. In: Darian-Smith K., Willis J. (eds). Designing Schools. Space, place and pedagogy, Routledge, Taylor\&Francis Group, London and New York (2017)

7. JISC Joint Information Systems Committee.: Designing Spaces for Effective Learning. A guide of 21 st century learning space design, Copyright HEFCE Higher Education Funding Council for England (2006)

8. OECD Centre for Effective Learning Environments.: Designing for Education. Compendium of Exemplary Educational Facilities 2011, pp.163-165, OECD Publishing (2011)

9. Gough, P.: BDP's Bridge Academy suggests an optimistic future for the design of school buildings, Architecture Today n.194, monographic number (2009) 
Open Access This chapter is licensed under the terms of the Creative Commons Attribution 4.0 International License (http://creativecommons.org/licenses/by/4.0/), which permits use, sharing, adaptation, distribution and reproduction in any medium or format, as long as you give appropriate credit to the original author(s) and the source, provide a link to the Creative Commons license and indicate if changes were made.

The images or other third party material in this chapter are included in the chapter's Creative Commons license, unless indicated otherwise in a credit line to the material. If material is not included in the chapter's Creative Commons license and your intended use is not permitted by statutory regulation or exceeds the permitted use, you will need to obtain permission directly from the copyright holder.

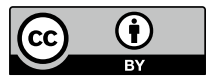

